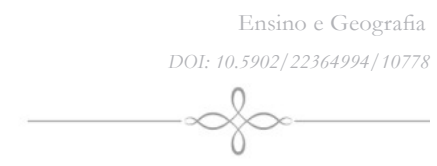

\title{
Ensino de Geografia: uso e aplicação de oficina de cartografia enfatizando as formas de orientação
}

Resumo: As oficinas têm contribuído de forma consistente tanto na construção do conhecimento do aluno quanto para o amadurecimento do professor. Assim sendo, esse trabalho é resultado do Projeto Pedagógico de Intervenção (PPI) desenvolvido pelos acadêmicos do Curso de Geografia da Unimontes - Universidade Estadual de Montes Claros com objetivo, entre outros, de fortalecer a prática docente na condição de futuros professores. Os objetivos principais foram: apresentar para os alunos como conhecer os pontos cardeais e colaterais; desmistificar a Cartografia enquanto ciência correlata à Geografia; ensinar os discentes a compreender melhor o que é um mapa e a se orientarem tendo como referência o Sol. Participaram da oficina estudantes do nível médio do ensino público das seguintes escolas Estaduais de Pirapora/MG e Buritizeiro/MG: E. E. José Maria Pereira; E. E. Fernão Dias; E. E. Coronel Ramos e a E. E. Argelci Motta. Nesse sentido, o caminho metodológico proposto partiu da revisão bibliográfica e documental, aplicação de oficina de Cartografia adaptada do Trabalho de Conclusão de Curso de Andréia Rodrigues Pandin apresentado em 2006 junto à Universidade Estadual de Londrina. A referida oficina ocorreu no espaço do prédio da UNIMONTES campus de Pirapora/MG, utilizando-se, entre outros recursos didáticos, de data show, quadro e giz. O principal resultado observado foi a participação e envolvimento intenso dos alunos no aprendizado da Cartografia, diferentemente dos relatos e experiências pouco animadores em sala de aula apontados no estudo bibliográfico sobre o ensino desta ciência geográfica no ensino fundamental e médio. As atividades trabalhadas que permitiram as observações foram: a produção de um mapa manuscrito; construção de uma Rosa dos Ventos na sala da Oficina e a realização de experiência de orientação pelo Sol.

\section{Teaching of Geography: use and application of mapping workshop emphasizing forms of guidance}

\begin{abstract}
The workshops has consistently contributed much in building the student's knowledge as to the maturity of the teacher. Thus, this paper is the result of Pedagogical Intervention Project (PPI) developed by academics from the School of Geography Unimontes - Universidade Estadual de Montes Claros aiming, among others, to strengthen teaching practice provided future teachers. The main objectives were: to introduce students to know the cardinal and collateral; Cartography while demystifying the science related to Geography; teach students better understand what a map and orient themselves with reference to water sun participated in the workshop students the average level of education of public schools following State Pirapora / Buritizeiro and MG / MG: E. E. José Maria Pereira, E. E. Fernão Dias, E. E. Colonel Ramos and E. E. Argelci Motta. Accordingly, the proposed methodological way left of bibliographic and documentary, application mapping workshop adapted Labour Completion Course Andreia Rodrigues Pandin developed in 2006 by the State University of Londrina. The workshop that took place in the space of the building UNIMONTES campus Pirapora / MG, where some were available teaching resources, including data show, blackboard and chalk. The main outcome was observed intense involvement and participation of students in learning Cartography, unlike the little stories and experiences animators classroom study mentioned in the literature on the teaching of geographical science in elementary and middle school. The activities worked that allowed the observations were: the production of a manuscript map; construction of a wind rose in the workshop room and conducting mentoring experience by the Sun.
\end{abstract}

\begin{abstract}
Samuel Ferreira da Fonseca*
Gustavo Lino Mendonça**

Danniella Carvalho dos Santos*

Vanderlete Ferreira Cardoso***

*Estagiários na CIA de Pesquisas de Recursos Minerais. Graduandos em Geografia pela Universidade Estadual de Montes Claros em Pirapora

**Técnico em Meio Ambiente, Técnologo em Gestão Ambiental e Cursa Geografia na UNIMONTES. Presidente do CODEMA de Buritizeiro - MG

*** Graduanda de Geografia pela Universidade Estadual de Montes Claros em Pirapora
\end{abstract} MG. MG.

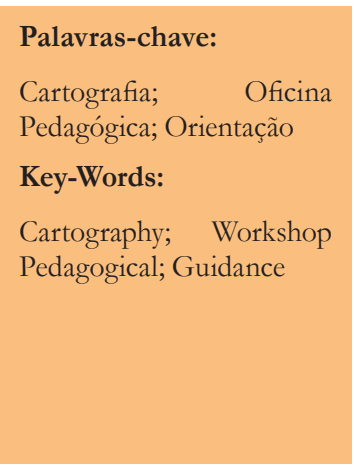

Geografia Ensino \& Pesquisa, vol. 17, n. 2, maio./ago. 2013 


\section{Introdução}

O aprendizado da Geografia na educação básica é de fundamental importância para o amadurecimento do processo de formação dos alunos que estão se preparando para as etapas seguintes da vida, pois, "a geografia proporciona o conhecimento do espaço geográfico que deve ser entendido, interpretado e analisado" (SOUZA, 2007 p. 23). Apesar de possuir o status de ciência de síntese, vai além da orientação no espaço, estuda também as constantes relações que se desenvolvem entre a sociedade e a natureza (ROSS, 2009). É, portanto, uma ciência de elevado prestígio em razão de sua importância para compreensão dos mais variados fenômenos espaciais (FONSECA, et al. 2011). Seja de natureza humana ou não, o que se desenvolve no espaço geográfico não escapa à análise em Geografia (ROSS, 2009).

Os conteúdos da geografia na escola básica diferenciam - se, em muito, daqueles ministrados no ambiente universitário (PONTUSCHKA, et al. 2007). No último predomina de forma latente a velha dualidade entre Geografia Física e Humana. Dualidade que, a nosso ver está longe de ser superada. Entretanto, vem deixando as suas marcas na sociedade por intermédio da Geografia escolar.

Na educação básica, observa-se a prática comum de se trabalhar os conteúdos geográficos de forma fragmentada. As razões podem ser alheias ao planejamento dos professores (eventos extra-classe súbitos) ou residir nas próprias limitações pedagógicas do docente, em se fazer a conexão entre conteúdos. Tal condição pode ocasionar, contraditoriamente, a mesclagem dos conteúdos, o que evidencia um esforço de síntese (porém, confuso para os alunos, quando mal trabalhado). Estuda-se, por exemplo: população, relevo, solo, indústria, clima e vegetação, quase que instantaneamente, provocando uma mistura capaz de afugentar os jovens aprendizes. Por fim, salienta - se que cada profissional, orientado por seu modelo de formação acadêmico/ideológico, atribui valor aos conteúdos de forma diferenciada, enfatizando o que está mais próximo de sua área de atuação dentro da Geografia em detrimento dos demais (PONTUSCHKA, et al. 2007; ROSS, 2009; GUIMARÃES, 2000).

Outro fato a se considerar é que, atualmente a escola disputa espaço com a mídia e a informática no cotidiano dos jovens. Os últimos são atraídos pela tecnologia (MONTEIRO, 2007). Assim, ao ensinar Geografia, não devemos dispensar a hipótese de que a própria tecnologia pode ser uma de nossas ferramentas de trabalho. Aproveitar a criatividade e vivência dos educandos para introduzir noções científicas pode, a nosso ver, contribuir no processo complexo de ensinar ou construir novos saberes.

Para Fitz, (2010) a primeira figura gerada no imaginário de um indivíduo ao falar de geografia é, sem dúvida, o mapa. Neste contexto, pensar o saber geográfico dissociado da compreensão cartográfica é, em última instância, uma tarefa antigeográfica. Quando o assunto é mapa, a Cartografia se sobressai mediante as demais áreas da Geografia, sendo inclusive de importância fundamental para o desenvolvimento e progresso de uma nação, devido a sua marcante presença desde a pré-história (SANTOS, et al. 2011). É exatamente esse saber que permite pensar em várias formas de gestão territorial. Ademais, a cartografia pode auxiliar no levantamento de estratégias de desenvolvimento.

Portanto, é indiscutível a importância da cartografia que, por sua vez, está presente constantemente no ensino e aprendizagem da geografia no ensino fundamental e médio. Desde a concepção do plano de unidade, passando pelos planos de aula, deve-se preocupar, sobretudo, com a maneira de ensinar e apreender os conceitos relacionados à localização e orientação no espaço (SOUZA, 2007). Entendemos que esta é uma tarefa da ciência geográfica e que a preparação por parte dos educandos (notoriamente deficiente na disciplina cartografia) conforme (SOUZA, 2007) é requisito fundamental para a dialética fluir quando da abordagem em sala de aula de conteúdos orientados por mapas. Libâneo (1994, p. 46) afirma que "A Geografia estuda as relações do homem com o espaço natural e como pode transformá - lo

Ensino de geografia: uso e aplicação de oficina de cartografia enfatizando as formas de orientação 
em seu benefício e em benefício da comunidade humana". Essas relações, por sua vez, sem a compreensão dos princípios cartográficos são difíceis de serem compreendidas pelos alunos.

Para Pandin (2006, p. 10) “.... a Cartografia é um instrumento necessário para o indivíduo em relação ao seu cotidiano". Portanto, elucidar questionamentos sobre essa temática na educação básica é uma necessidade que não se restringe aos educandos, mas está presente entre docentes, inclusos aí (o que é ainda mais grave) entre os que ministram a disciplina de Geografia.

A oficina objeto de pesquisa deste trabalho objetivou o amadurecimento dos acadêmicos enquanto estagiários, que logo estarão inseridos no mercado, permitindo a prática do planejamento, o uso da criatividade e de recursos tecnológicos, além de outros métodos pedagógicos.

O objetivo do presente artigo é apresentar a importância do uso das oficinas pedagógicas não apenas durante o estágio curricular, mas também apontá-la como um poderoso recurso didático para ser utilizado no ensino dos conteúdos que envolvem a cartografia, favorecendo tanto o ensino quanto a aprendizagem, tão deficiente no cotidiano das escolas do ensino fundamental e médio do Brasil.

\section{Oficina de cartografia: conceitos, aplicações e ensino}

Para Afonso, (2006) as oficinas estão diretamente relacionadas aos trabalhos realizados em grupo. Nestas, o foco está ligado em uma questão central que o grupo propõe a elaborar dentro de um contexto social. "A Oficina pode ser útil nas áreas de saúde, educação e ações comunitárias" (AFONSO, 2006, p.9). Neste trabalho utiliza-se do referido recurso na educação visando a difusão do saber cartográfico.

Souza, (2007) argumenta que a maioria dos estudantes não são alfabetizados cartograficamente. E isto, para a autora, procede desde as séries iniciais do ensino fundamental.

Conhecer os pontos cardeais e colaterais, compreender conceitos de latitude e longitude, coordenadas UTM (Universal Transversa da Mercator), Geóide, Elipsóide, Datum, escala, dentre outros conceitos, são necessidades básicas para que o aluno tenha um bom senso geográfico que influenciará não apenas na sua relação com a disciplina Geografia, mas multidisciplinarmente.

Para tanto, o docente que pretende trabalhar esses conceitos no ensino médio terá que enfrentar alguns desafios. Além da formação acadêmica muitas vezes deficiente, das limitações quanto ao acesso a recursos didáticos e do acúmulo da deficiência em várias séries, conforme comentado anteriormente, é indispensável à compreensão do momento social e político no qual estamos inseridos, suas contradições e conflitos para melhor abordar os saberes em sala de aula (GUIMARÃES, 2000).

Neste contexto, ao estudar a Cartografia, é necessária a inserção da mesma no contexto da atualidade. Usá-la como ferramenta para interpretar os acontecimentos e saber onde estão os fenômenos do cotidiano. Necessário é, antes de tudo, apresentar para o aluno que ele necessita desse saber pois a aprendizagem do aluno não deixa de ser suscitada pelos seus anseios e por sua necessidade (LIBÂNEO,1994).

A Cartografia pode ser entendida como a ciência, arte e técnica de conceber, levantar, redigir e divulgar os mapas (Joly, 1990), ao concluir o ensino médio o aluno deve, se quisermos qualidade na formação educacional, possuir base sólida dessa ciência.

Entretanto, vem ocorrendo sérias mudanças no saber cartográfico, principalmente após a década de 1970, quando introduziram as tecnologias computacionais na seara geográfica (FITZ, 2010). Esses acontecimentos permitiram dinamizar não só a Cartografia, mas também

Geografia Ensino \& Pesquisa, v. 17, n.2 p. 147-156, maio/ago. 2013

Fonseca, S. F; Mendonça, G. L; Santos, D. C. ; Cardoso, V.F.

ISSN 2236-4994 
os seus conceitos. Tais fatores tornam no mínimo temerário o ensino dessa disciplina de forma estática. Hoje, a mesma requer uma postura atualizada e versátil do docente. Temos aí um fator favorável ao ensino da cartografia, pois conceitos como geoprocessamento, sensoriamento remoto, Sistemas de Informação Geográfica, trouxeram a tecnologia para a Cartografia e, conforme mencionado na introdução, a afinidade dos jovens por recursos tecnológicos, com interfaces atraentes em ambiente computacional, podem convergir para um processo mais amigável, favorecendo consideravelmente a aprendizagem.

Nesse sentido, a aplicação de oficinas pedagógicas para aperfeiçoar o aprendizado dos alunos tem sido ferramenta imprescindível no processo de ensino - aprendizagem, agindo também como meio de interação entre educandos e educadores, dispensado àquela educação bancária onde esse diálogo é dispensado (FREIRE, 1996).

Por conseguinte, esta possibilita o desenvolvimento do discente, gerando uma postura de maior responsabilidade, permitindo a construção do conhecimento e não uma simplória memorização de conteúdos. Pois, conforme Libâneo, (1994, p. 104) "A aprendizagem é um processo de assimilação de conhecimentos escolares por meio de atividades própria dos alunos".

Conforme Pandin, (2006, p. 10) “... os conteúdos relacionados à Cartografia são fundamentais desde as primeiras etapas do ensino, uma vez que este prioriza as diferentes formas de representação do espaço geográfico.” Assim sendo, é fundamental o professor elaborar maneiras diferenciadas para tratar o referido assunto.

De acordo com Maciel et al, (2008) para melhor desempenho da aprendizagem dos alunos, o professor deverá estar sempre apto a mudanças de paradigmas. Quando necessário, deve-se buscar alternativas que possibilitem envolver os alunos de forma agradável. Por isso, deve-se considerar a alternativa de se lançar mão das oficinas, ferramentas de apoio devido a sua flexibilidade e capacidade de envolver o educando a ponto de reduzir as distancias entre conteúdo teórico e a prática em Cartografia.

\section{Metodologia}

Esse trabalho é resultado do Projeto Pedagógico de Intervenção (PPI) desenvolvido pelos acadêmicos do Curso de Geografia da Unimontes - Universidade Estadual de Montes Claros.

O PPI teve o objetivo de fortalecer a prática docente dos estagiários na condição de futuros professores. Os acadêmicos responsáveis pela aplicação da oficina, sob a orientação da professora regente, perceberam uma tendência dos professores de geografia que, em sala de aula, se afastam dos conteúdos de exatas que, inevitavelmente, estão presentes na Cartografia, isto em decorrência do grau de complexidade. Tal prática tem ocasionado uma sub-cultura, deixando a cartografia marginalizada em função da exigência de certo nível de domínio do ensino da matemática. Este fator pode ser a causa da omissão do Conteúdo Cartografia por parte de muitos professores que lecionam no ensino básico no Brasil.

O critério para a escolha do tema da oficina foi precedido de pesquisa realizada nas

Geografia Ensino \& Pesquisa, v. 17, n. 2 p. 147-156, maio/ago. 2013

Ensino de geografia: uso e aplicação de oficina de cartografia enfatizando as formas de orientação escolas Estaduais de Buritizeiro, (E. E. José Maria Pereira) e Pirapora/MG, (E. E. Fernão Dias; E. E. Coronel Ramos e a E. E. Argelci Motta) junto aos docentes da disciplina geografia das mencionadas instituições. Foram os professores que informaram, mediante entrevista, quais conteúdos consideravam mais críticos, carentes de reforço escolar devido a baixa produtividade dos alunos verificada através de avaliações e participação. A maioria dos professores apontou a Cartografia.

A oficina foi dividida em três momentos: abertura; apresentação dos conceitos cartográficos e realização de experiência de orientação tendo por referência o Sol. Na abertura 
foram apresentados os monitores e o tema de forma sucinta; na conceituação foram abordadas algumas noções de cartografia e gerado um mapa em papel "chamex" tamanho A4; na atividade relativa a orientação, foi utilizado o sol como referência e desenhado com giz colorido uma Rosa dos Ventos no piso da sala.

Utilizou - se de revisão bibliográfica em: Ross, (2009); Ramos, (2005); Guimarães, (2000); Pontuschka, et al. (2007); Libâneo, (1994); Freire, (1996) dentre outros. Estudo documental e aplicação de oficina de Cartografia adaptada do Trabalho de Conclusão de Curso de Andréia Rodrigues Pandin desenvolvida em 2006 apresentado junto à Universidade Estadual de Londrina.

O espaço utilizado para aplicação da oficina foi a área do prédio da UNIMONTES campus de Pirapora/MG. Foram disponibilizados alguns recursos didáticos inclusive projetor de mídias "data show", quadro e giz, além de cartolina, pincéis, lápis de cor, cartolina colorida e tesouras.

Objetivando maior interação entre os alunos, a sala foi dividida em três grupos com cinco alunos de escolas diferentes. Foram construídos pelos alunos: mapas, sóis e uma rosa dos ventos com os pontos cardeais e colaterais.

\section{Resultados da oficina e atividades práticas}

A oficina pedagógica foi intitulada da seguinte forma: "Localização Espacial por meio da Cartografia" e teve como foco a interação entre os monitores e os alunos.

Conforme Silva et al, (2008) é necessário que o docente tenha noção de que os educandos possuem experiências e vivências, capaz de produzir um aprendizado mútuo, garantindo, dessa forma, a participação dos alunos no processo de ensino aprendizagem. E é neste ambiente, de envolvimento e interação, que as dinâmicas favorecem aspectos cognitivos.

A seguir é apresentado um mapa criado pelos alunos na primeira parte da oficina, após alguns esclarecimentos sobre a Cartografia.

Figura 01 - Mapa de Localização de Pirapora - MG

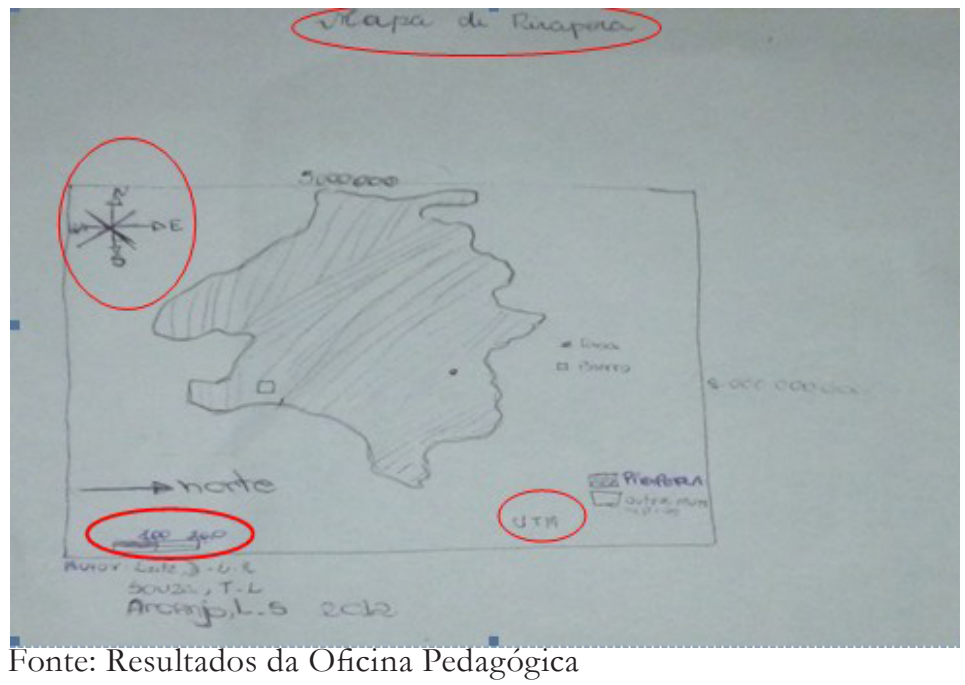

Geografia Ensino \& Pesquisa, v. 17, n.2 p. 147-156, maio/ago. 2013

O mapa de localização de Pirapora foi elaborado por um grupo de três alunos. Neste, percebemos a internalização instantânea dos conceitos apresentados na oficina. Na porção superior esquerda do mapa notamos uma rosa dos ventos com pontos cardeais. Destacamos a informação ambígua quanto à orientação do mapa (uma seta apontando o norte diferente da 
rosa dos ventos). Apesar disso, a criatividade e agilidade em apresentar os conceitos ensinados, em um tempo limitado, aponta para a internalização de conceitos complexos como sistemas de projeção, escala, título e orientação (circulados na figura).

Para Joly, (1990) há uma grande defasagem a respeito dos conhecimentos cartográficos desde as séries iniciais, pois não se aprende a fazer mapas como se aprende a ler e escrever. Nesse sentido, a oficina pôde aproximar os alunos da cartografia de forma a conduzí-los a prática imediata da construção e interpretação de mapas.

Na figura 02, é apresentada uma representação do Globo Terrestre, criada pelos alunos durante a oficina.

Figura 02 - Globo Simplificado com Coordenadas Geográficas

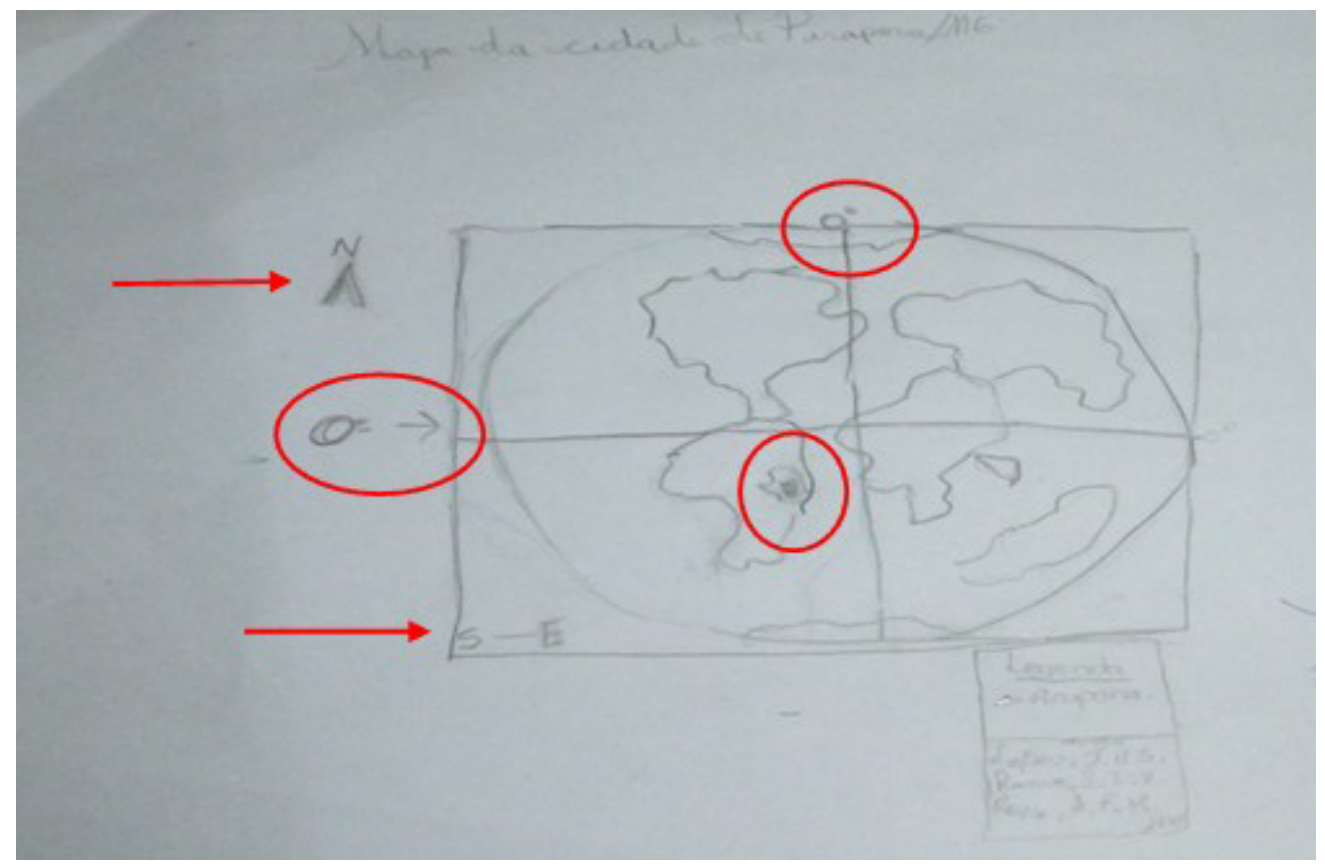

Fonte: Resultados da Oficina Pedagógica

Nota - se na figura 03 as duas alunas de pé, procurando a direção Leste, (nascente) dentro da sala de aula. Essa atividade ocorreu às $9 \mathrm{~h} 25 \mathrm{~min}$ da manhã, fato que gerou algumas dificuldades para os alunos encontrarem a direção pretendida, haja vista o Sol ter se elevado do horizonte demasiadamente. Por fim, os sóis foram colados na parede e no teto da sala por um dos monitores da oficina, demonstrando aos presentes que estava se orientando pela indicação das alunas com os braços estendidos.

Percebemos os resultados preliminares da oficina, onde os alunos criaram um mapa representando todo o Globo Terrestre, incluindo o Meridiano de Greenwich $\left(0^{\circ}\right.$ de longitude) e a linha do Equador ( $0^{\circ}$ de latitude). Nota-se ainda a localização de Minas Gerais e de Pirapora, na concepção espacial dos alunos. Nessa figura ocorreu ambigüidade novamente na orientação, como percebemos por meio das setas acima.

No segundo momento da oficina foi realizada uma prática de orientação tendo por

Geografia Ensino \& Pesquisa, v. 17, n.2 p. $147-156$, maio/ago. 2013

Ensino de geografia: uso e aplicação de oficina de cartografia enfatizando as formas de orientação

I ISSN $2236-4994$ referência o Sol. Nesta atividade, os alunos foram divididos em três grupos, momento em que realizaram as seguintes tarefas: recorte de uma figura do Sol (cada grupo elaborou um Sol), em uma cartolina amarela e de quatro setas, para servirem de pontos cardeais a serem fixados no piso da sala.

$\mathrm{Na}$ sequência, foram escolhidos aleatoriamente alunos para apontarem com o braço direito para a direção leste (posição do Sol naquela hora da manhã, figura 03) permitindo gerar 
certo senso de orientação a partir da localidade em que ocorreu a oficina, haja vista que, nesta época do ano, o Sol nasce a Leste.

Figura 03 - Alunas apontam para o trajeto do sol durante o dia

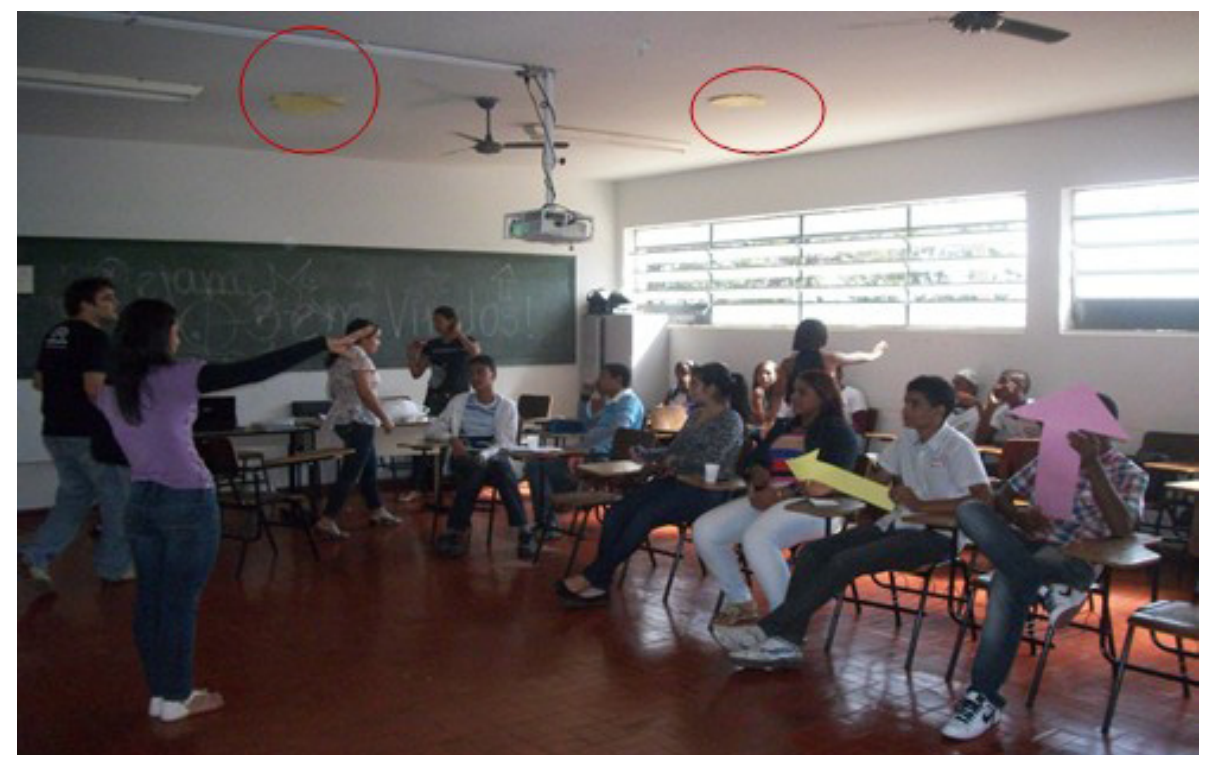

Foto: FONSECA, S. F. 2012

Posteriormente, desta vez orientando-se pelos sóis colados na parede e teto da sala, iniciou-se a confecção de uma rosa dos ventos no piso da sala. Abaixo (figura 04), se percebe o início da construção da rosa dos ventos pelos alunos.

Figura 04- Aluno apontando para o Leste

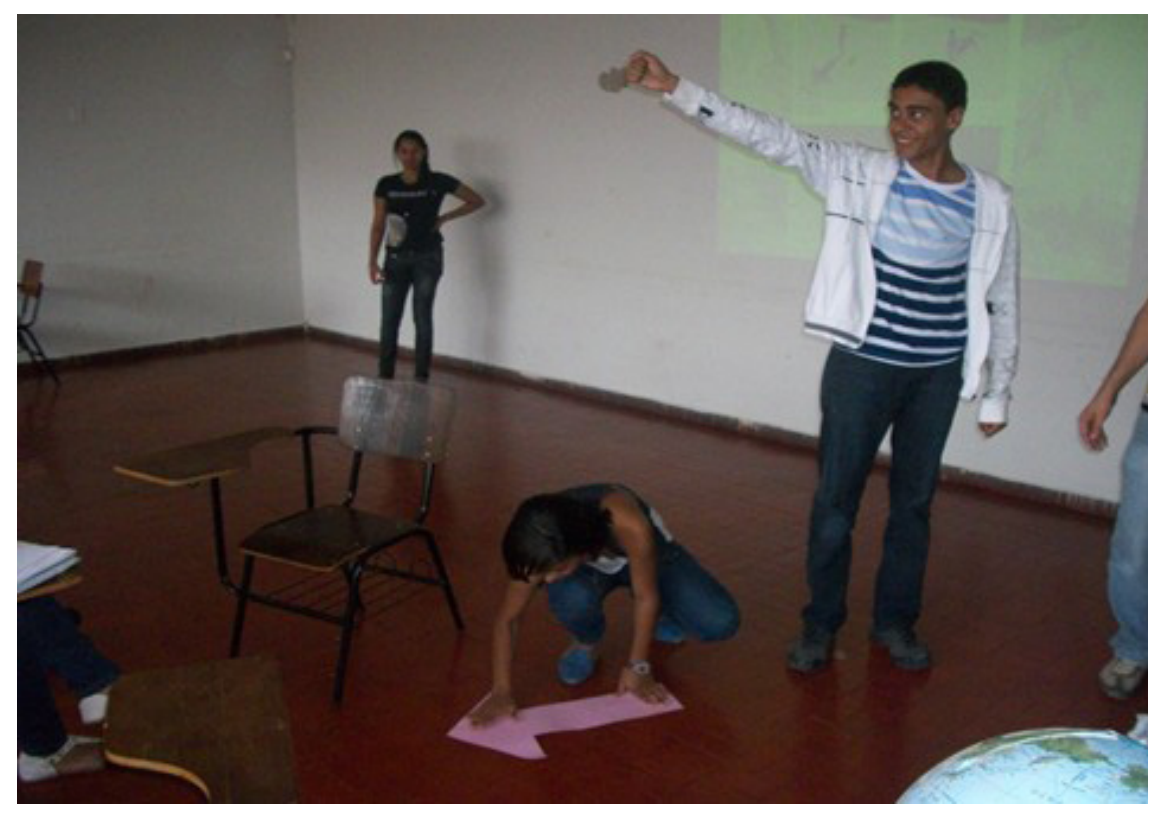

Foto: FONSECA, S. F. 2012

O resultado final da atividade de orientação tendo por referência o Sol é apresentado na figura 05 , abaixo. Os alunos foram convidados aleatoriamente para a construção de uma rosa dos ventos. Nesta fase foram coladas no piso da sala as setas confeccionadas pelos grupos formando os pontos cardeais e posteriormente, utilizando-se do giz, foram inseridos os pontos colaterais.

Geografia Ensino \& Pesquisa, v. 17, n.2 p. 147-156, maio/ago. 2013

Fonseca, S. F; Mendonça, G. L; Santos, D. C.; Cardoso, V.F.

ISSN 2236-4994 
Figura 05- Rosa dos Ventos no piso da sala onde ocorreu a oficina

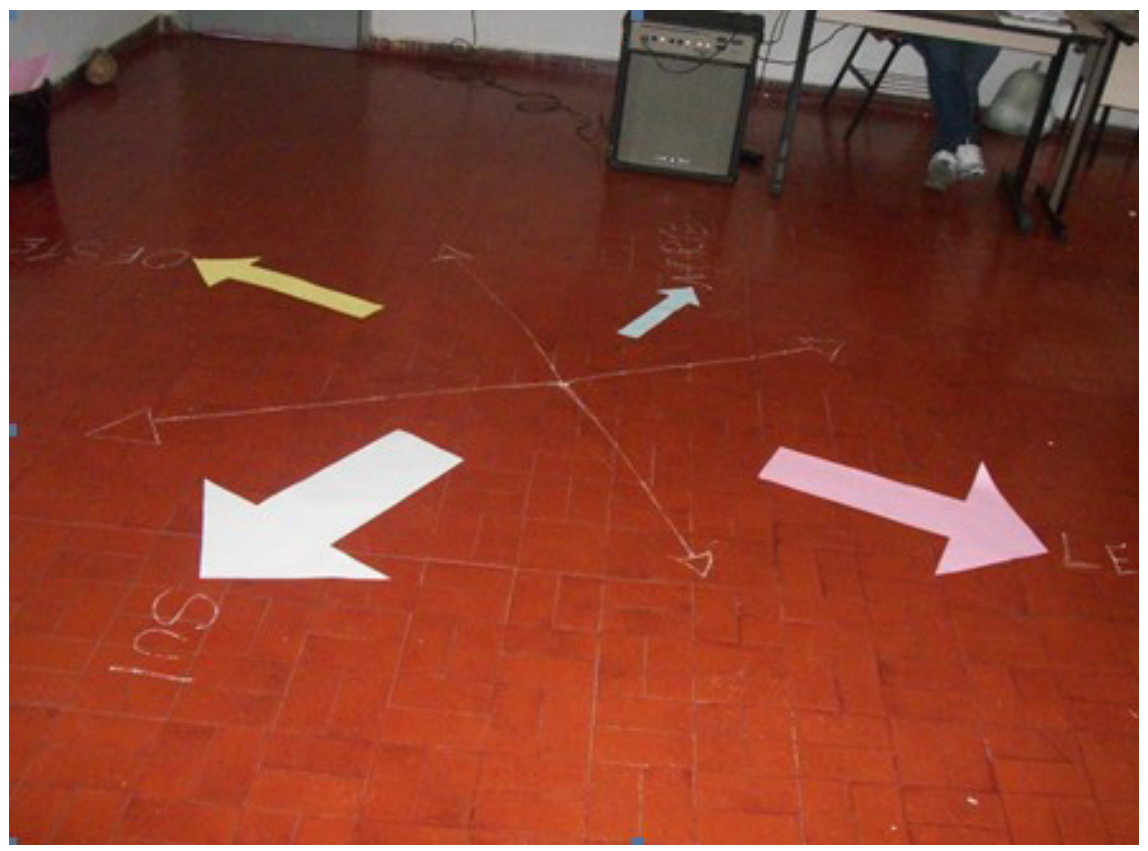

Foto: FONSECA, S. F. 2012

Percebe-se as setas orientadas inseridas pelos alunos no piso da sala. Essas foram fixadas seguindo os procedimentos anteriores. A primeira seta inserida foi a que apontava para o Leste, de acordo com a posição do Sol durante o horário da oficina.

Um aluno posicionou-se em posição de "Cristo Redentor" conforme imagem projetada em sala com "data show" e seu braço direito apontou a direção Leste. Dessa forma, os demais alunos encontraram os pontos cardeais e colaterais conforme fora - lhes apresentado pelos monitores.

Foi notável a interação e disposição dos alunos quanto à participação na oficina. Dessa forma, os mesmos tiveram a oportunidade de desmistificar preconceitos como, por exemplo, a pouca utilidade de geografia na vida das pessoas ao mesmo tempo em que foi combatida a sub-cultura de que a Cartografia ensinada na educação básica é de difícil aprendizado, tudo isto de forma simples, sem dispor de recursos tecnológicos, assim como os povos antigos.

Conforme Ramos, (2005) a cartografia foi, em seus primórdios, interativa, permeando por um período de estagnação e retornando a interatividade. Por este ângulo, a oficina pedagógica permite estimular a interatividade entre o discente e o conteúdo ministrado e construir um diálogo mais acessível entre professor e aluno. $O$ ambiente descontraído e a dinamicidade das oficinas diferenciam em muito estas, das aulas ministradas de forma habitual.

Importante destacar que as metodologias geralmente mais aplicadas em sala de aula (aula expositiva dialogada, quadro e giz, uso de mapas, etc.) cumprem papel fundamental ao expor o conteúdo a ser trabalho. Portanto, não é recomendável a atuação no ambiente escolar somente com oficinas, dinâmicas e atividades lúdicas. Acreditamos que estas precisam ocorrer com maior frequência nas escolas, de forma a diversificar a maneira de construir o conhecimento pautando - o na interação.

Geografia Ensino \& Pesquisa, v. 17, n. 2 p. $147-156$, maio/ago. 2013

Ensino de geografia: uso e aplicação de oficina de cartografia enfatizando as formas de orientação

\section{Considerações finais}

Percebemos a importância das oficinas pedagógicas para despertar a interatividade nos discentes mediante os saberes cartográficos intrísecos no cotidiano. Atualmente, a dinamicidade se torna um pressuposto inerente à educação onde aulas estáticas e sabatinais se tornaram cada vez mais inviáveis. 
A nosso ver, a oficina superou as expectativas. A interação dos alunos ocorreu de forma natural e, consequentemente, as atividades foram aplicadas e desenvolvidas com sucesso. Tal dinâmica permitiu aos acadêmicos, na condição de monitores, o amadurecimento profissional com ênfase para o planejamento, o uso da criatividade, a interatividade e o trabalho em equipe, além da formação da concepção de que não existe conteúdo difícil de se ministrar ou totalmente averso, inacessível aos interesses dos alunos da educação básica.

O principal resultado observado foi a quebra do paradigma de que ensinar e aprender Cartografia no ensino médio é tarefa árdua tanto para os docentes quanto para os discentes. Os relatos de experiências pouco animadores em sala de aula, apontados durante a pesquisa inicial para a escolha do tema da oficina, corroborados pelos estudos bibliográficos, sobre a maneira de ensinar e aprender cartografia no ensino fundamental e médio, foram parcialmente contraditados. Parcialmente por que não se pretende esgotar a temática, que deve ser objeto de pesquisas para os incontáveis viés que certamente irá apontar, na tentativa de esclarecer as relações entre as ciências cartográficas na vida dos discentes e docentes do ensino básico no Brasil.

As atividades trabalhadas que permitiram as observações foram: a produção de um mapa manuscrito; construção de uma Rosa dos Ventos na sala da Oficina e a realização de experiência de orientação pelo Sol.

Nessas atividades a interação entre docente e discente ocorreu de forma agradável e dinâmica, fatores que facilitaram o trabalho. Sendo a interação uma das constantes mais complexas de se obter em aulas comumente denominadas de "normais".

Sugere-se a realização de atividades correlatas no decorrer do ano letivo com outras disciplinas, de forma que a interação seja uma constante cada vez mais ampla e consistente nos estabelecimentos de ensino.

Como a Geografia possui um leque muito amplo de saberes, a escolha por apenas uma de suas áreas pode contribuir para amadurecimento no assunto, todavia, no ensino médio é a Cartografia que continua sendo mais negligenciada. Portanto, esse trabalho fica justificado na necessidade de ampliar os saberes na área cartográfica e na forma de transmitir esse saber, expondo as oficinas pedagógicas enquanto possibilidades.

\section{Referências bibliográficas}

AFONSO, Maria Lúcia M. Oficinas em dinâmica de grupo: um método de intervenção psicossocial. São Paulo. Casa do Psicólogo, 2006.

CALLAI, Helena Copette. Estudar o lugar para compreender o mundo. In: Ensino de Geografia: práticas e textualizações no cotidiano. Porto Alegre: Mediação, 2003.

FIALHO, Daniela Marzola. 2010. Cidades Visíveis: para uma história da cartografia como documento da identidade urbana. Universidade Federal do Rio Grande do sul. (Doutorado em História) Porto Alegre.

FITZ, Paulo Roberto. Geoprocessamento sem complicação. Oficina de Textos. São Paulo, 2010.

FONSECA, S. F.; SANTOS, S. M.; MARINS NETO, W. 2011. A Geografia Como Instrumento de Análise das áreas de Potencial Turístico em Buritizeiro - MG. I Seminário de Ciência, Tecnologia e Gestão. Faculdade de Ciência e Tecnologia Alto Médio São Francisco FAC-FUNAM. p. 02-10. Pirapora/MG. Anais...

FREIRE, Paulo. Pedagogia da Autonomia: saberes necessários a prática educativa. Papirus. São Paulo. 1996

GUIMARÃES, Iara Vieira. Ensinar e aprender geografia: contexto e perspectivas de professores e alunos

Geografia Ensino \& Pesquisa, v. 17,
n.2 p. 147-156, maio/ago. 2013

Fonseca, S. F; Mendonça, G. L; Santos, D. C. ; Cardoso, V.F.

ISSN 2236-4994 
como sujeitos sócio-culturais. IN: Revista Olhares e Trilhas. Universidade Federal de Uberlândia UFU, Uberlândia/MG. Vol. 1, n. 1, 2000, p. 08 - 39.

JOLY, Fernand. A Cartografia. Tradução de Tânia Pelegrini. Campinas-SP: Papirus, 1990.

LIBÂNEO, José Carlos. Didática. São Paulo. Cortez, 1994. (Coleção Magistério. $2^{\circ}$ Grau. Série: Formação do professor).

MACIEL, Flávia Elaine Alves; GUIMARÃES, Jussara Maria de Carvalho; BRITO, Monica Pereira Rocha. As Práticas docentes inovadoras como impulso para aprendizagens significativas. IN_REVISTA Educação, Escola e Sociedade. Montes Claros. ANO I, V. I, 2008. p.121-128.

MONTEIRO, Fausto de Oliveira. 2007. Diagnóstico das dificuldades encontradas pelos estudantes do Ensino Médio em aprenderem os conteúdos de Geografia na Escola Estadual Luiz BalbinoPirapora/MG. Trabalho de Conclusão de Curso (Licenciatura em Geografia) Universidade Estadual de Montes Claros. Pirapora/MG. Departamento de Geociencias. 81p

PANDIN, Andréia Rodrigues. 2006. Oficina pedagógica de cartografia: uma proposta metodológica para o ensino de geografia. Trabalho de Conclusão de Curso (Bacharelado em Geografia) Universidade Estadual de Londrina. Departamento de Geociencias. 78p.

PONTUSCHKA, Nídia Nacib, et al. A disciplina escolar e os currículos de Geografia. IN: PONTUSCHKA, Nídia Nacib.; PAGNELLI, Tomoko Ihyda.; CACETE, Núria Hanglei. Para Ensinar e Aprender Geografia. São Paulo, Cortez, 2007. P. 59 - 86.

RAMOS, C. S. Visualização Cartográfica multimídia: conceitos e tecnologias. São Paulo: Editora UNESP, 2005.

ROSS, Jurandyr Luciano Sanches. Ecogeografia do Brasil: subsídios para planejamento ambiental. São Paulo: Oficina de Textos, 2009. $1^{\mathrm{a}}$ reimpressão.

SANTOS, Cátia dos.; PEDROTTI, Alceu.; MATOS, Alda Lisboa de.; SANTANA, Ana Paula Silva de. A Cartografia e o ensino da Geografia. In: Revista Geográfica da América Central. Número especial EGAL, 2011. Costa Rica. II Semestre. p. 1 - 15.

SILVA, Érika Oliveira; FERNANDES, Luciana Aquino; MENDES, Tatiane Aparecida; FONSECA, Verônica Alkimim; GUIMARÃES, Jussara Maria de Carvalho. As propostas inovadoras e sua interferência no cotidiano escolar. IN_REVISTA Educação, Escola e Sociedade. Montes Claros. ANO I, V. I, 2008. p.129-136.

SOUZA, Jeanne Consuely Soares. 2007. O Ensino da Cartografia na 5a série da Escola Estadual Luiz Balbino-Pirapora/MG. Trabalho de Conclusão de Curso (Licenciatura em Geografia) Universidade Estadual de Montes Claros. Pirapora/MG. Departamento de Geociencias. 69p.

\section{Correspondência:}

Samuel Ferreira da Fonseca - Rua Vicente Rocha, No 285. Bairro Jardim dos Buritis. Buritizeiro-MG

Cep: 39280-000

E-mail: samuelsig@gmail.com

Geografia Ensino \& Pesquisa, v. 17, n. 2 p. $147-156$, maio/ago. 2013

Ensino de geografia: uso e aplicação de oficina de cartografia enfatizando as formas de orientação

Recebido em 28 de junho de 2012.

Revisado pelo autor em 07 março de 2013.

Aceito para publicação em 12 de abril de 2013. 